\section{A SERIES OF CASES TREATED BY THE INJECTION OF BACTERIAL VACCINES.}

BY EDWARD TURTON, M.D., B.Sc. VICT., M.D. LEEDS, M.R.C.P. LOND.;

AND

ALFRED PARKIN, M.D., M.S. LOND., F.R.C.S. ENG., CONSULTING SURGEON TO THE VICTORIA HOSPITAL, HULL.

IN presenting this series of cases we assume knowledge on the part of our readers of the excellent work done by Sir A. E. Wright and his co-workers and also by Dr. W. Bulloch and Dr. G. T. Western at the London Hospital, to all of whom we are considerably indebted. With three exceptions the cases have all been treated in our private practices in which the difficulties are obviously greater than in hospital practice. Our object has been to ascertain what advantages are to be derived from this mode of treatment and by the application of applied bacteriology to both medicine and surgery. We have endeavoured by working together to benefit by mutual criticism and comparison of clinical signs ; this coöperation has undoubtedly resulted in a great increase in the interest of the work and has reduced in some measure" by such criticism, the faults of observation and errors of deduction. The opsonic estimations and bacteriological investigations have all been the work of one of us (E. T.) but the rest of the work has been done conjointly.

In recording these cases we have included all under regular and constant treatment by this method, irrespectively of the results obtained. Previously to treatment we have, whenever possible, ascertained the exact causal germ of the disease by microscopical and cultural investigations and have estimated the opsonic index of the patient for that particular germ. In the majority of instances we have found it necessary to isolate the exact strain of microorganism and establish its causal relationship to the disease in each case. At first we were under the impression that all infections due to any micro-organism could be treated by a vaccine containing that morphological variety of organismfor instance, a staphylococcic infection by a vaccine made of any strain of staphylococci, on the assumption that all strains were more or less identical. Such a plan of treat ment, however, did not give what we considered satisfactory results and further experience has shown us that the greatest success in this treatment is attained by the cultural separation of the exact strain of organism peculiar to the patient and by the preparation and use of a vaccine prepared from that organism. This has been done in nearly all our cases but obviously the procedure entails not only a great amount of work but also a certain bacterial knowledge. This plan seems at present inapplicable to tuberculous affections but considering the multitudinous clinical and pathological manifestations of tuberculous disease we think that ultimately some such differentiation of strain will have to be carried out in preparing a special tuberculin for each group of patients or possibly for each patient. So far the difficulties of obtaining a pure culture of the special strain of tubercle bacillus have prevented us from carrying out our investigations on these lines. To this cause we attribute our want of success in the treatment of some of the tuberculous bone affections-e.g., Cases 3,22 , and 23and to us one of the undoubted causes of failure seems to be the fact that Koch's new tuberculin (TR) as supplied has been used indiscriminately for multitudinons affections caused possibly by varying strains of the tubercle bacillus. If this were not the case how can it be explained that patients may have localised lupus or caries for years, possibly half a lifetime, without developing internal tubercle and that clinically tuberculous infections are classified as lung tubercle, brain tubercle, serous membrane tubercle, \&: each pursuing a more or less definite course and not necessarily leading one to the other.

In isolating the causal germ it soon became obvious that there might be more than one present, the tubercle bacillus, for example, being associated with staphylococci, pneumococci, \&c. Tuberculous skin affections have almost necessarily a secondary affection of pus forming organisms, as was found in both cases of lupus here recorded. In Case 7 (lupus with extensive suppuration) the tuberculous opsonic index was 0.45 , and the staphylococcic opsonic index 0.65 ; although this patient was not injected with any staphylococcic vaccine the staphylococcic opsonic index rose to normal and remained normal as soon as the tuberculous opsonic index arrived at, and was maintained above, the normal line, thus indicating that the staphylococcic infection was purely secondary, resulting from the presence of a suitable nidus. Similarly pulmonary tuberculous affections are subject to superimposed infection and the difficulty here is to estimate the anount of damage due to the secondary organisms. In Case 14 (chronic pulmonary tuberculosis) the pneumococcic opsonic index was 0.8 and a greater improvement was noticeable on the injection of a pneumococcic vaccine, and the raising of the pneumococcic opsonic index to $1 \cdot 5$.

In advanced cases of pulmonary tuberculosis the invading organisms may be multiple, consequently useful therapeutic measures may be difficult to apply; for instance in Case 2 the staphylococcic opsonic index was found to be $1 \cdot 25$, indicating that she was at that time also fighting a staphylococcic invasion. As the result of staphylococcic injections the staphylococcic opsonic index was raised to $1 \cdot 66$. The ingrafting of other organisms on the tubercle bacillus is well illustrated by Case 9 , in which after six weeks' drainage of a tuberculous kidney she was treated with tuberculin; again, six weeks later, a staphylococcus albus having been found in the discharge and the sinuses not healing, she was treated with a vaccine of this organism, which vaccine raised the staphylococcic opsonic index from 1.15 to 1.5. After these injections, combined with the tuberculin, healing became more rapid and finally complete.

The possibility of the association of the tubercle bacillus with the bacillus coli communis in intestinal conditions is illustrated by Case 25, in which an apparently tuberculous mass to the right of the umbilicus yielded slowly to tuber culin but much more rapidly to a combined injection of tuberculin and a vaccine of the bacillus coli. In support of this view the bacillus coili opsonic index was before injection 1.0 ; subsequently it reached 1.4 coincidently with the clinical improvement.

It is difficult to say in any one case how often the injections should be repeated, because acute infections differ very greatly from chronic ones. A bacillus coli infection may be fatal in a few days or even hours; acute general tuberculosis in a few weeks; on the other hand, a case of chronic pulmonary tuberculosis or furunculosis may drag on for years. The only safe guide seems to be to inject as soon as the index, when once raised, shows signs of falling. We have found it advisable to inject a case of acute pulmonary tuberculosis at intervals of about five days with marked benefit, and a case of bacillus coli peritonitis even more frequently with gratifying success.

So far as we can judge each case is a law unto itself, both as to dosage and also as to frequency of repetition; the only guidance is obtained by frequent estimations of the opsonic index and a careful study of the opsonic chart. Our plan has been to treat each case on its merits, usually beginning with a small dose, watching the behaviour of the index, and continuing this dose, increasing or diminishing it as the occasion seems to demand. In the more acute cases the negative phase seemed to be either entirely absent or of very short duration, the opsonic index taken after the first 24 hours showing a marked rise compared to the height on injection.

We have had no ill-effects from any injection, no abscesses, no rigors, and no rash; in a few cases only a feeling of malaise for about 24 hours.

Prophylaxis.-It seems to us that there is a distinct future for those cases apparently threatened with tuberculosis by environment, contiguity, and possibly heredity, by the injections of bacterial vaccines. We have had one such case in a member of a family with marked tuberculous history his sister at the time was under this treatment. He had no physical signs but there were definite loss of weight, cough, and night sweats. There were no tubercle bacilli in the sputum. The tuberculous opsonic index was 0.97 , raised by injection to 1.54 with accompanying improvement in general health and increase of weight. We have had no experience of prophylactic injections against the bacillus coli; this appears seldom possible in the emergencies of private practice.

Faulures. - We have failed to do any good in the following four cases.

CASE 1.-The patient, a male, aged 33 years, was seen with Dr. W. A. Bryant of Hull. He suffered from advarced 
pulmonary tuberculosis with right empyema; an operation was performed during which he nearly died. The tuberculous opsonic index three days after the operation was $0 \cdot 87$. He was injected three days later with iojoth of a milligramme of tuberculin (TR) when the tuberculous opsonic index was 1.02 . 24 hours later it was 0.71 and after 48 hours it was $1 \cdot 46$. Death occurred 44 days after injection. With our present knowledge we should hesitate to inject in a similar case.

CASE 2.-A female, aged 16 years. There was advanced pulmonary tuberculosis of four years' duration. There were o cavity at the left apex and consolidation of the remainder of that lung, with subsequent formation of empyema, for which operative measures were declined and consequently treatment was discontinued. The tuberculous opsonic index before treatment was 0.85 and two days later it was 1.04 the highest point reached under treatment being $1 \cdot 6$. With the formation of the empyema the tuberculous opsonic index fell to $0 \cdot 93$. Treatment was continued for ten weeks and the weight increased four pounds. The number of opsonic estimations being 19 and the number of injections seven. The case is now in statu quo.

CASE 3.-A male, aged 36 years. This was an almost bopeless case of hip and spinal disease dating from boyhood there were multiple sinuses. The tuberculous opsonic index before treatment was 0.98 and the highest point reached under treatment was $1 \cdot 7$. The discharge from the sinuses contained staphylococcus pyogenes albus, the index for which was $1 \cdot 19$, rising after injections to $1 \cdot 65$. Some improvement took place, with a gain in weight of four pounds, but later there was a relapse, with the formation of an intrapelvic abscess. The duration of treatment was 16 weeks. The tuberculin injections numbered 11 and the staphylococcic injections seven, while the opsonic estimations were 34. The case is now practically in statu quo.

CASE 4.-A female, aged six years, under the care of Dr. J. Sarege of Hull. This was a case of tuberculous mening itis, following on gland of the neck, of the duration of one week. The tuberculous opsonic index was $1 \cdot 19$. The patient was injected with $\frac{1}{10}$ th of a milligramme of tuberculin (TR). There were some diminution of headache and slight improvement in the mental condition, followed by convulsions and sudden death five days later. Curiously, the gland disappeared before death.

Bacillus coli infections :-

CASE 5.-A male, aged 48 years, under the care of Dr T. de Carle Jackson of Hull had been ill for three weeks with acute abdominal pain at intervals, sickness and rigors swelling in the epigastrium, and gradual loss of flesh. No plasmodia malariæ were found. The patient was operated upon under the impression that he had some pancreatic affection; the pancreas was found to be normal but two large gall-stones were removed from the gall-bladder. There was no improvement after operation; the rigors continued and there was a gradual loss of all subcutaneous fat. There was no abdominal distension but the patient appeared seriously septic without actual pus formation. He was sent home to die. The gall-bladder secretion was examined and a pure culture of bacillus coli communis was obtained. No blood culture was made. The bacillus coli opsonic index before injection was $0 \cdot 93$. The injection of $500,000,000$ of bacillus coli vaccine produced improvement and raised the index to $1 \cdot 14$. Three days later the last rigor took place. Two subsequent injections were given and the bacillus coli opsonic index rose to $1 \cdot 68$. In four weeks the patient was quite well. (Fig. 1.)

OASE 6.-A male, aged 28 years, under the care of Dr. Bryant. The patient had a sudden attack of abdominal pain followed by development of acute general peritonitis. $\mathrm{He}$ was operated upon on the fourth day, the cause of the peritonitis being obscure. An abscess in the pelvis was simply drained, no attempt being made to wash out the peritoneal cavity ; in fact, it was impossible on account of adhesions. From a culture of the pus the bacillus coli communis was obtained and a vaccine was made. The index for this organism was $0 \cdot 8,48$ hours after operation; the opsonic index of the blood taken at the time of the operation, for a laboratory culture of bacillus coli, was 1.13. An injection of $500,000,000$ of his own vaccine was made three days after the operation with some improvement in the condition of the patient and a rise of the index to 1.22 . Four subsequent injections were made and the highest index reached was $1 \cdot 79$. (Fig. 2.) There was a noticeable drop of the index on the thirteenth day after the operation; this was found to be due to retained pus in the pelvis; with the evacuation of the pus the index rose in 24 hours to $1 \cdot 17$. The patient has now no abdominal symptoms but there is decided thickening in the region of the appendix. The wound is almost healed (five weeks after operation).

These are the only cases of bacillus coli infection which we have treated, but they seem to us worthy of record, as we feel certain that but for the injection of the vaccine they would both have died. Case 5 seems to us to be an example of bacillus coli septicrmia.

Iuberculous Infections-1. Tuberculosis of the skin.

CAsE 7.-The patient, a male, aged ten years, was sent by Dr. E. Harrison of Hull. There was extensive lupus of the face and the limbs (in all 34 separate patches) with partial destruction of one ear. Tubercle bacilli were found in the scrapings. All previous treatment had been useless in arresting the disease. The tuberculous opsonic index before treatment was 0.45 and the highest point reached during treatment was $1 \cdot 75$. There was a secondary infection of staphylococcus pyogenes aureus, the opsonic index of which rose from 0.65 to normal coincidently with the improvement due to tuberculin injections. All the patches on the face are healed and those on the limbs are nearly cured. The duration of treatment has been 28 weeks and the patient is still under treatment. Number of tuberculin injections 20 ; tuberculous opsonic estimations, 40 ; and staphylococcic estimations, 5 .

CASE 8.-The patient, a male, aged 10 years, was sent by Dr. A. McC. Erskine of Goole. There was extensive lupus of eight years' duration. The right ear was nearly destroyed and the nose partially so. There was extensive ulceration of the palate, the upper lip, and the cheeks. There were a large patch six inches in circumference on the back of the right thigh and a large patch on the left foot extending over the great and second toes. Tubercle bacilli were found. Several previous operations more or less successful had been followed by fresh infection. The tuberculous opsonic index, which before treatment had been $0 \cdot 9$, was raised to a maximum of $1 \cdot 7$ under treatment. The right ear and the left foot healed, the patch on the thigh nearly healed, and the nose and palate rapidly improved. There was no fresh infection. Number of tuberculin injections, 13 ; opsonic estimations, 16 ; duration of treatment, 18 weeks. The case is still under treatment.

Both these cases of lupus seem to us to have improved much more rapidily than we should have expected under any other form of treatment; the rapid improvement in general health after a few injections was most marked. In each case the previous treatment had been of a varied character.

2. Tuberoulous disease of the kidneys.

CAsE 9.-A female, aged 21 years. There was a history of pyuria of two years' duration. 13 years ago the patient had undergone excision of the right hip-joint (performed by one of us, A. P.) for tuberculous disease. The right kidney, which was much enlarged, was painful. There was a hect ic temperature. The kidney was opened vertically and many large caseous foci were scraped out. The kidney was drained. Tubercle bacilli were discovered in the urine. Two months later, as the general condition of the patient was not satisfactory, the tuberculin treatment was commenced. The tuberculous opsonic index was 0.9 ; it was raised to a maximum of $1 \cdot 6$ under treatment. The staphylococcus pyogenes albus was found in the discharge from the sinus and the index for this organism was raised from normal to 1.4. There followed marked improvement in the general health, the closing of the sinus, and an increase in weight of seven pounds. 'The duration of treatment was 16 weeks. Number of tuberculin injections, 10 ; staphylococcic injections, 5 ; tuberculous opsonic estimations, 28 ; and staphylococcic estimations, 7.

CASE 10 -A male, aged 15 years. There was a history of wasting and pyuria extending over two and a half years. There were tubercle bacilli in the urine. The right kidney was enlarged and tender. The tuberculous opsonic index before treatment was $1 \cdot 13$; it was raised by injections to a maximum of $1 \cdot 83$. Number of tuberculin injections, 7 and opsonic estimations, 20 . The case has been under treatment for ten weeks and is still under treatment. The kidney is now scarcely palpable, there is only a trace of pus in the urine, and tubercle bacilli are very difficult to find. A marked improvement in the general bealth has taken place and an ncrease in weight of three and a half pounds.

In Case 9 the disease was so extensive that a nephrectomy 
1132 THE LANCET, 」⿰DR. E. TURTON \& MR. A, PARKIN : INJECTION OF BACTERIAL VACCINES. [OCT. $27,1906$.

FIG. 1.



FIG. 2.

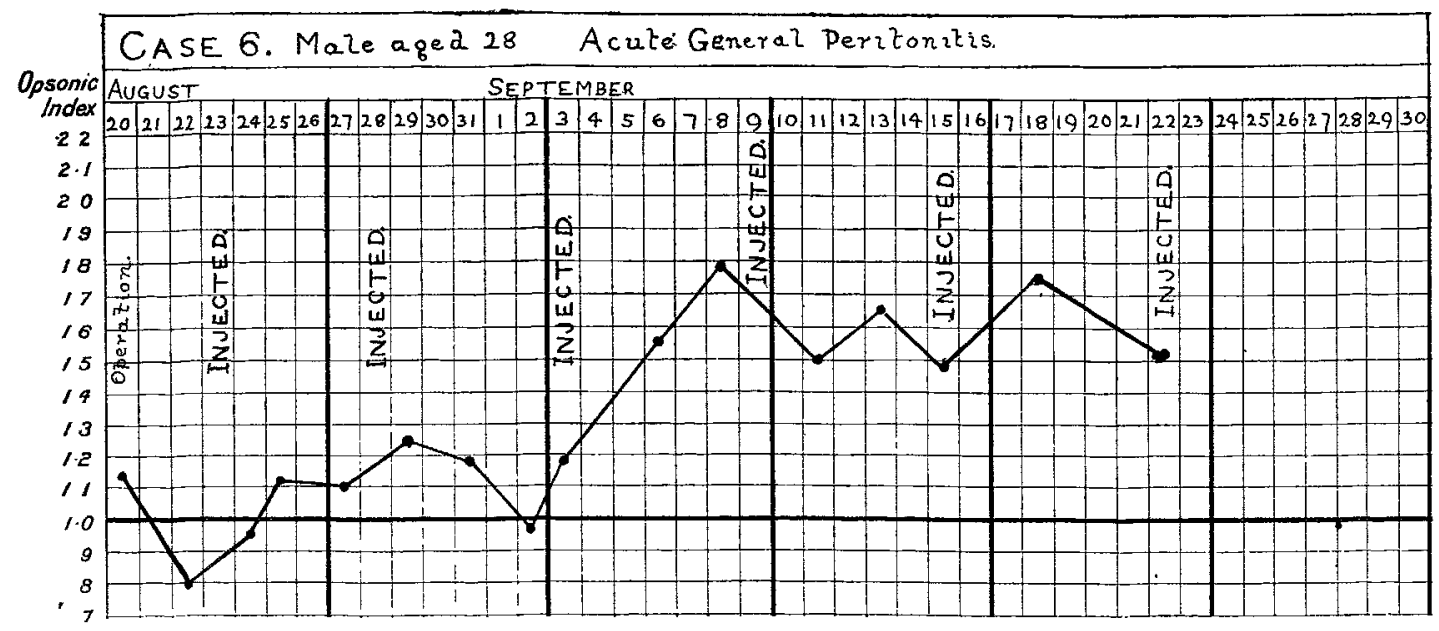

FIG. 3.

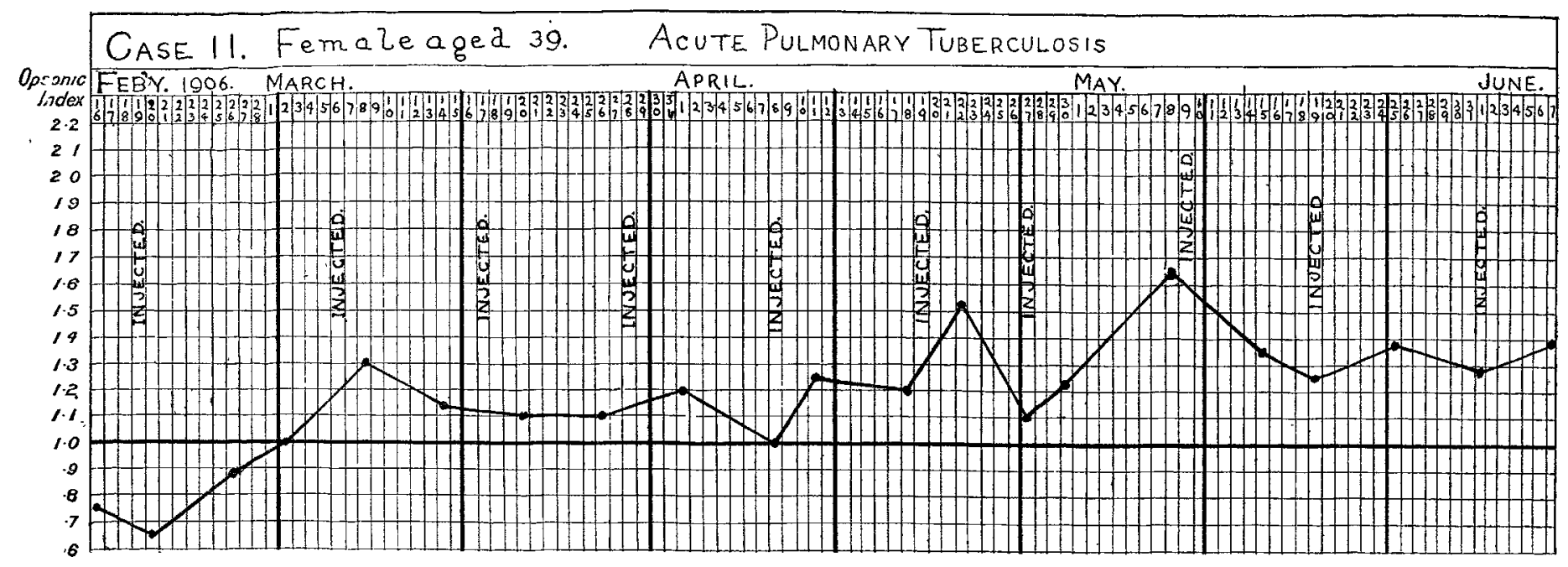

FIs. 4.

Case 16. Maleaged 34. Acute Pulmonary Tuberculosis.

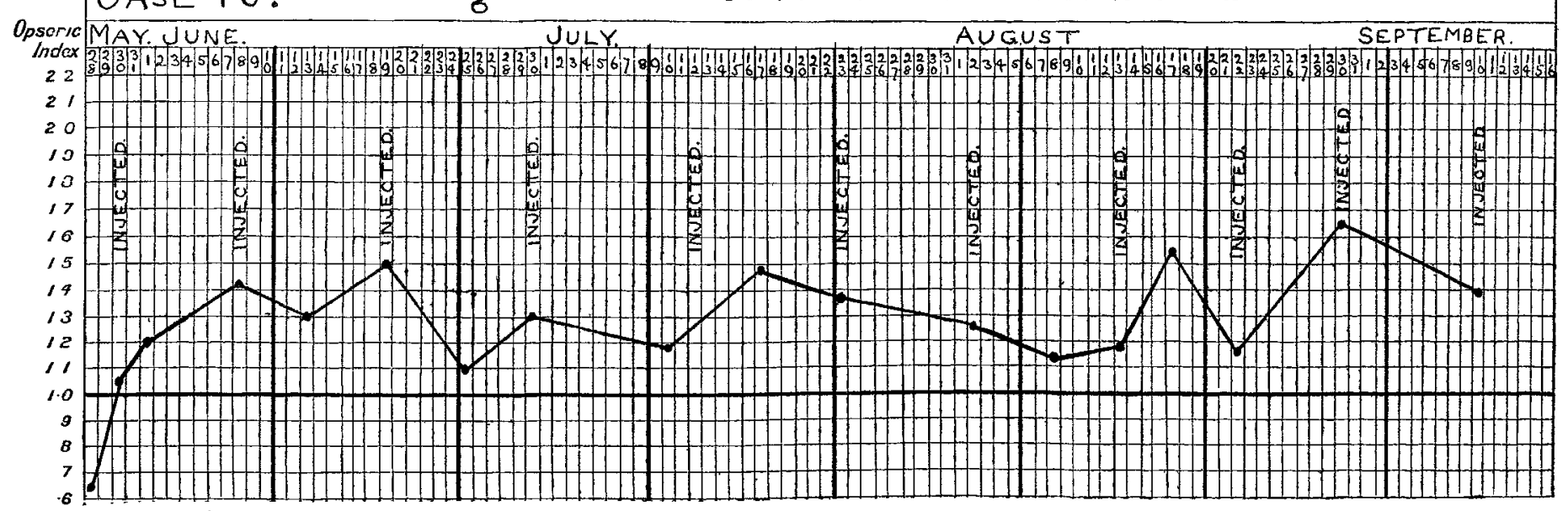


seemed impossible; in Case 10 it has not so far been required on account of the success of this treatment.

3. Pulmonary tuberoulosis.

CASE 11.-The patient was a female, aged 39 years, under the care of Dr. A. T. Brand of Driflield. There was a history of cough of six months' duration, with failing health and loss of weight. The patient was confined to bed and had a hectic temperature. There were signs of consolidation at the right apex. Tubercle bacilli were found in the sputum. The tuberculous opsonic index, which before treatment was $0 \cdot 75$, was raised to a maximum of $1 \cdot 63$. The number of the tuberculin injections was 10 and the opsonic estimations were 22. Duration of treatment four months. There is now no cough or expectoration and there is an increase in weight of 19 pounds. The physical signs are negative. The patient has resumed her ordinary duties and considers herself cured. (Fig. 3.)

CASE 12.-The patient, a male, aged 27 years, was under the care of Dr. Angus Fairweather of Pocklington, had had failing health and had lost nine pounds in weight during the previous six months. There were hæmorrhagic sputum, dulness and râles at the right apex, and a caseous gland with a sinus at the right side of the neck. The tuberculous opsonic index before treatment was 0.82 ; it was raised by injection to a maximum of 1:55. The staphylococcic index was 1 . Number of tuberculin injections, 5 ; and opsonic estimations, 11. Duration of treatment seven weeks. The patient gained in weight 13 pounds. The gland disappeared, the sinus healed, and the physical signs became negative. The patient says that he has never felt in better health.

CASE 13.-The patient, a male, aged 44 years, was seen with Dr. J. B. Close of Hull. There was a history of cough and blood-stained sputum extending over six months. The loss in weight had been nine pounds. Tubercle bacilli were found in the sputum. On two occasions there had been severe hæmoptysis, There were signs of extensive consolidation at the left apex and in a less degree at the right. The tuberculous opsonic index before treatment was 0.62 ; the highest point reached under treatment was $1 \cdot 74$. Number of tuberculin injections, 13 ; and opsonic estimations, 19 . Duration of treatment six months. The abnormal physical signs have disappeared and tubercle bacilli have not been found in the sputum in the last six examinations. There bas been an increase in weight of $16 \frac{1}{2}$ pounds and the patient has been at work for the last three months.

CASE 14.-The patient, a male, aged 41 years, was sent by Dr. Harrison. There had been long-standing pulmonary tuberculosis with recrudescence during the last seven months, during which the loss of weight had been four pounds. There were signs of consolidation and of a cavity at the left apex. Tubercle bacilli were found in the sputum. The tuberculous opsonic index, which before treatment had been $1 \cdot 39$ and $1 \cdot 37$, rose under treatment to $1 \cdot 9$. The pneumococcic opsonic index was $0 \cdot 8$, rising to $1 \cdot 4$ after injections of a pneumococcic vaccine. Tuberculin injections, 14 ; pneumococcic injections, four ; and opsonic estimations, 26. Duration of treatment five months. The patient's weight is stationary at 11 stones. Improvement is shown in the general health but there are still a few râles at the left apex. No tubercle bacilli have been found in the last six examinations of the sputurn.

CASE 15.-The patient, a male, aged 31 years, was sent by Mr. E. H. Howlett with a history of cough and loss of weight during the preceding 12 months. Improvement was made under three months' sanatorium treatment but later a relapse took place. There were signs of consolidation of the left upper lobe. Tubercle bacilli were found in the sputum. The tuberculous opsonic index taken on two occasions before treatment had been 0.84 and 0.85 ; it was raised by injection to 1.64 and has been maintained above the normal for the past three months. Number of tuberculin injections, 21 ; and opsonic estimations, 44 . The weight has increased from 13 stones 10 pounds to 14 stones 4 pounds during six months' treatment and is now stationary. There are still a few râles at the left apex and occasionally tubercle bacilli are discovered in the sputum. The patient is still under treatment.

CASE 16.-The patient, a male, aged 34 years, was sent by Dr. F. N. Stewart. There was a history of cough and expectoration which had lasted for nine months. There had been failing health and loss of weight. There was consolidation of the left apez and tubercle bacilli were found in the sputum. The tuberculous opsonic index before injection had been 0.65 and 1.05 ; it was raised by injection to a maximum of $1 \cdot 64$. This index has not fallen below $1 \cdot 15$ since the treatment was commenced. Number of tuberculin injections, 13; and opsonic estimations, 18. Duration of treatment 15 weeks. There is still some dulness at the left apex; tubular breathing is no longer heard but there are occasional râles. There has been a gain in weight of eleven and a half pounds. Active disease has apparently been arrested but there are still tubercle bacilli in the sputum. (Fig. 4.)

The results of these cases of pulmonary tuberculosis are distinctly gratifying, more especially as there was no other concurrent treatment and as many of the patients were able to continue their usual avocations throughout. It appears that the more chronic the case, the more likely is the tuberculous opsonic index at the initial examinations to be below normal, whereas in the acute cases the opsonic index is either high or low, representing fluctuations in immunising power. In the acute cases it seems more difficult to maintain a constant high level of opsonic power, on account of the interference by reaction to the toxins periodically absorbed into the blood stream. Both acute and chronic cases have benefited by the treatment, but it is obviously difficult to say in any one case when an absolute cure has been attained.

\section{Tuberculous glands.}

CASE 17.-The patient was a male, aged six years. There were multiple enlarged glands on both sides of the neck, recurrent after operation ten months before. This was practically an old case of scrofula. It was pronounced to be inoperable. Several of the glands were fiuctuating; these were simply opened (without scraping) during the course of treatment. The tuberculous opsonic index before injection was 1 ; the highest point reached under treatment was 1.4. Number of tuberculin injections 7 ; and opsonic estimations, 11. Duration of treatment 13 weeks. All the glands have disappeared and all the wounds have healed. The general health is greatly improved.

CASE 18.- The patient, a female, aged 17 years, was sent by Dr. H. D. Johns of Hornsea. There was a large breakingdown mass of glands of the size of an orange at the right angle of the jaw. She refused operation. Aspiration was resorted to and tubercle bacilli were found in the pus. The tuberculous opsonic index before treatment was $1 \cdot 1$ and the opsonic index of the serum from the pus was 0.7. A drainage-tube was inserted under ethyl chloride. The opsonic index rose under treatment to $1 \cdot 65$. Number of tuberculin injections, 12 ; and opsonic estimations, 13 . Duration of treatment 18 weeks. A small lump of the size of a hazel nut is still present; the sinus is closed; and the general health is much improved.

CASE 19.-The patient was a female, aged 43 years, who was sent by Dr. W. Murray of Hessle. There was a history of enlarged glands of the neck and the axilla of four years' duration. Two extensive operations involving partial removal of the right pectoral muscle had been performed. There was recurrence on both sides of the neck and the case was pronounced to be inoperable. There were cedema of the right arm down to the fingers, multiple matted glands on both sides of the neck, lymphatic enlargement of the left axilla, an enlarged spleen, and internal to this there was a mass of glands in front of the spine. The tuberculous opsonic index before treatment was 0.95 ; the highest point reached under injection was $1 \cdot 5$. Number of tuberculin injections, 15 ; and opsonic estimations, 16 . Duration of treatment five months. There are four or five small isolated glands in the left posterior triangle, which could now be easily removed, and a hard gland in the left axilla; the rest have disappeared. The spleen and the mass over the spine are no longer palpable but there is still some cedema of the arm and forearm. The general health is excellent. The case is still under treatment.

CASE 20.-A female, aged four years, under the care of Dr. C. H. Milburn, had multiple glands on both sides of the neck with much matting together for 18 months. The largest gland on the left side was of the size of a walnut. The tuberculous opsonic index before treatment was 0.9 and 1.13 ; the highest point reached after injections was $1 \cdot 59$. Number of tuberculin injections, 8 ; and opsonic estimations, 12. The largest gland broke down and had to be incised. Duration of treatment, 13 weeks. The glands on both sides have almost disappeared and the sinus has healed.

CASE 21. - A female, aged 21 years, had had for five months a mass of glands in the right posterior triangle with considerable matting together and extending beneath the 
sterno-mastoid and trapezius. The tuberculous opsonic index $\mid 1 \cdot 1$; the highest point reached under treatment was $1 \cdot 5$. before treatment was 0.76 and the highest point reached after injection was $1 \cdot 45$. Number of tuberculin injections, 7 ; and opsonic estimations, 10 . The case is still under treatment. The glands are much more discrete, smaller, and harder.

Tuberculous glands are obviously amenable to this treatment, but whether their complete absorption when once caseous is possible seems doubtful. The periadenitis first subsides, then the capsule of the gland becomes thinner, but the caseous centre remains and may require removal. We have proved this by removing or incising glands at various stages of the treatment purely for the purposes of this investigation. Case 21 suggests the advantage of this treatment; for tuberculous mediastinal and abdominal glands otherwise inaccessible.

95. Tuberculous bone disease.

CASE 22.-The patient, a male, aged 46 years, was under 12. The sinus is in statu quo, but the general health bas much improved.

OASE 24.- The patient, a male, aged 22 years, was sent by Dr. Harrison. He suffered from tuberculous disease of the right elbow. The first operation had been performed 16 years ago and the case had been treated by excision two and a half years ago. An abscess was opened on March 20th and tuberculin treatment was commenced one month later. There was great thickening round the elbow. joint and a sinus which was almost closed. The tuberculous opsonic index, which before treatment was 0.9 , rose after injections to $1 \cdot 65$. Number of tuberculin injections, 12 ; and opsonic estimations, 21. The sinus has healed completely, all thickening around the elbow has disappeared, and the general health is excellent. The case was under treatment for 18 weeks.

FIG. 5.

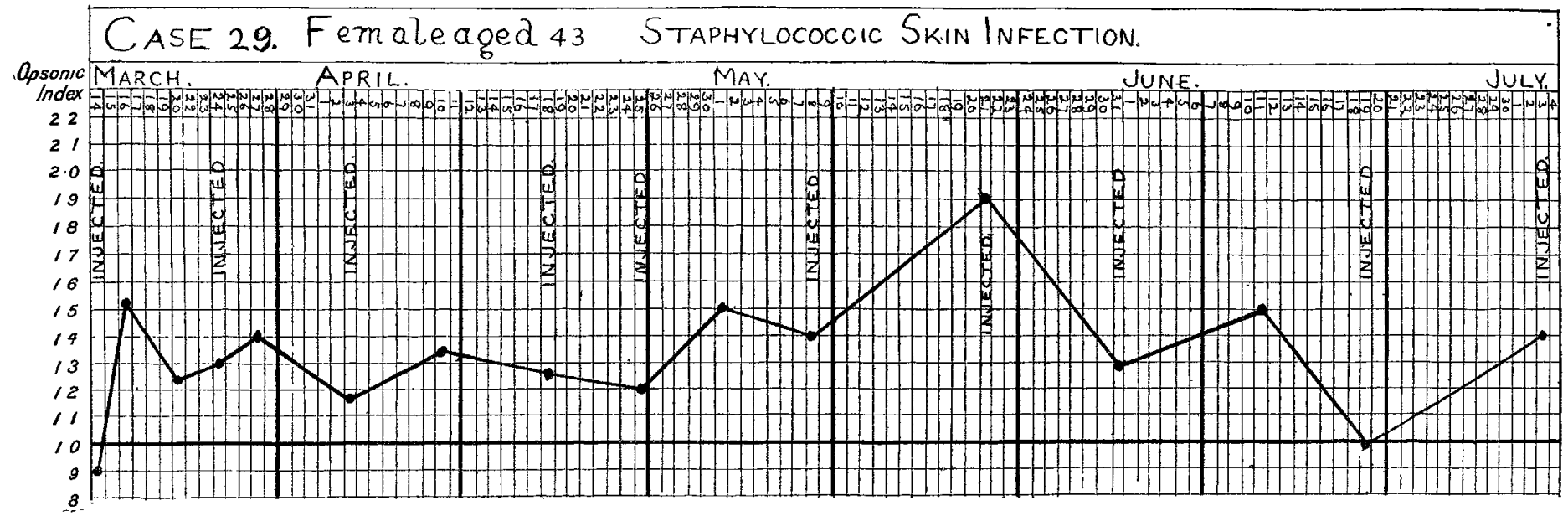

Fig. 6.

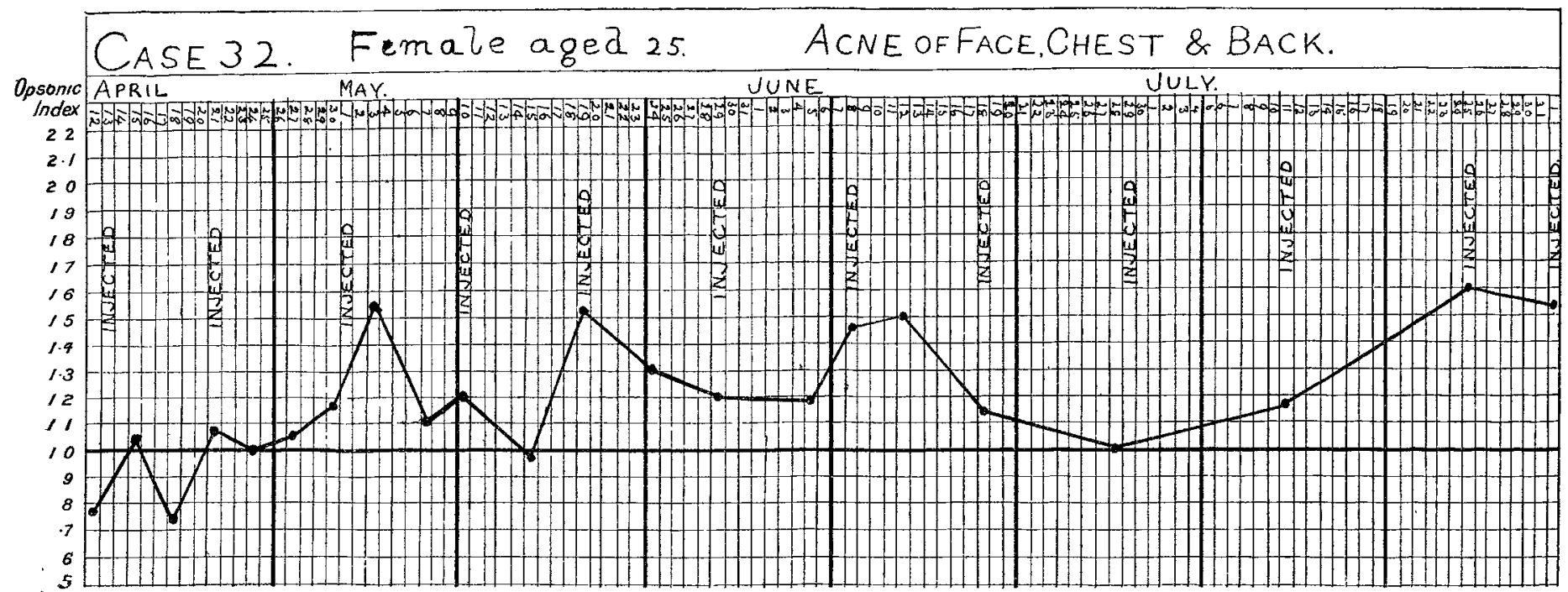

the care of Dr. J. J. Coleman of Bridlington. There had been caries of the fourth lumbar vertebra of one and a half years' duration, the first symptoms being very obscure. Subsequently there was development of abscesses in the right loin, the right iliac region, and the left loin. Treatment by tuberculin commenced eight months after the last operation. The tuberculous opsonic index before injection was 0.71 ; it was raised under treatment to a maximum of $1 \cdot 64$. Number of tuberculin injections, 13 ; and opsonic estimations, 24 . The staphylococcus pyogenes albus was cultivated from the pus; the opsonic index for this organism was $1 \cdot 15$ and it was raised by injection to $1 \cdot 41$. Duration of treatment six months. The patient has much improved in general health and appearance; two sinuses have healed and there is now very little discharge from the third.

CASE 23.-A male, aged 11 years. This was a case of old laminectomy for cervical caries and paraplegia five years before. The result had been eminently satisfactory, but the patient had a sinus on the right side of the neck in the posterior triangle. Treatment was directed to the cure of the sinus. The tuberculous opsonic index before injection was

\section{Intestinal tuberculosis.}

CAsE 25.-A male, aged 27 years, sent by Dr. G. Briggs, had had recurrent attacks of colic for 18 months, with the gradual formation of a mass in the right iliac fossa. He was operated upon in March, 1906, and the appendix was found to be healthy, the mass being thought to be tuberculous, and the abdomen was closed. Opsonic treatment was commenced five months later, the mass then being as large as a duck's egg. The tuberculous opsonic index taken on two occasions had been 0.96 and 0.98 ; this was raised by injection to a maximum of $1 \cdot 7$. The bacillus coli opsonic index five weeks later was 0.7 and a vaccine of this organism raised the index to $1 \cdot 4$ with much more rapid improvement. Number of tuberculin injections, 13 ; bacillus coli injections, 8 ; and opsonic estimations, 29. The case is still under treatment. The mass is about one-third of its former size and is much more moveable. Attacks of pain are experienced at very rare intervals and then they are only slight. The patient has returned to his work.

CASE 26. -The patient, a male, aged 18 years, was sent by Dr. Harrison. An appendicular abscess had been opened 
and drained 11 months ago; a sinus persisted and a fæcal fistula formed. Seven months later there were acute epigastric pain, abdominal distension, and rise of temperature. Diaphragmatic pleurisy was diagnosed. Four months later there was more epigastric pain and the diaphragm was almost fixed. There were adhesions between the stomach, the spleen, and the diaphragm, which were separated by operation, and a frcal fistula which passed down to the appendix was closed. Subsequently there was a daily rise of temperature to $103^{\circ} \mathrm{F}$., with rigors. There were suspicious physical signs in the chest but no tubercle bacilli were found in the scanty sputum. The condition was desperate and was thought to be tuberculous. The tuberculous opsonic index taken on two occasions was 1.27 and 1.31. The highest point reached after injection was 1.68. Number of tuberculin injections, 12 ; and opsonic estimations, 23. Duration of treatment five months. Except for very occasional slight diaphragmatic pain, the patient is now quite well and at work. There has been an increase in weight of 23 pounds.

The patients in the last two cases were in a desperate condition when the treatment was commenced and the success attained is very gratifying.

Staphylococcic affections.

CASE 27.-A surgeon, aged 41 years, had had frequent infections on the hands, the wrists, and once on the knee by inoculation of hair follicles without any open wound. These inoculations were followed by various septic conditions, on two occasions endangering life and surgical work had almost to be relinquished. Susceptibility to staphylococcus invasion was established and at the suggestion of Sir A. E. Wright the corresponding vaccine was injected. By means of regular injections the index has been maintained above normal $(1 \cdot 2$ to $1 \cdot 3)$ for some months. The patient reports that he has had no serious infection for the last nine months, is in excellent health although in constant work, and is able to continue his surgical work without fear of being laid up.

CASE 28.-A medical man, aged 38 years, had a carbuncle on the left buttock for ten days, followed by an inflamed papule beneath the left ear. The staphylococcic opsonic index before treatment was 0.6 ; after the first injection it rose to 1.42. The carbuncle began to clear up and the papule below the ear, which had suppurated, became quite localised, the surrounding cellulitis becoming circumscribed. The opsonic index fell to 0.9 and there was a rapid increase in the cellulitis below the ear with formation of a slough. After two more injections this cellulitis became circumscribed. A third infection arose over the second dorsal spine but the opsonic index being now kept above 1.2 this infection did not cause the least cellulitis, nor was it at all painful but aborted in about three or four days. The patient has since been quite well. Number of staphylococcic injections, 5 ; and opsonic estimations, 12. The case was under treatment for five weeks.

CASE 29.-A female, aged 43 years, had been under ordinary treatment for five months for multiple recurring papules, becoming pustular with subsequent formation of granulomatous patches on the wrists, the forearms, and the front of the legs. The patches on the legs at one time formed large plaques several inches in circumference. The patient was treated for scabies and syphilis without benefit. All other treatment was unavailing. A staphylococcus pyogenes albus was isolated and the staphylococcic opsonic index was found to be 0.9 ; this was raised by injections to 1.9. Number of injections given, 14 ; and opsonic estimations, 12. Duration of treatment, three months. All patches are cured but if there is any recurrence a single injection clears it up. (Fig. 5.)

The result of the treatment in this case of staphylococcic skin infection suggests to us that there is room for a modernised system of nomenclature of skin diseases, one division of which would contain the diseases due to microorganisms. The present system of differentiation largely by means of the discoverer's name is so chaotic as to be bopeless.

CASE 30.-The patient, a male, aged 39 years, had had sycosis of the whole of the beard of six months' duration. Various forms of medical treatment were tried with very slight benefit. Staphylococcus pyogenes aureus was cultivated from pus. Staphylococcic opsonic index before treatment, 0.9 ; highest point reached as the result of injection, 1.58. Number of injections, 12; opsonic estimations, 11. Duration of treatment four months. The patient is now cured, but we admit the possibility of a re-infection.

The result of this form of treatment in such cases contrasts very favourably with that obtained by other means; it leaves no scar as frequently happens after treatment by the $x$ rays.

CASE 31.-The patient, a female, aged 44 years, had had pustular eruption on the nose, cheeks, and chin of many years' duration. All previous treatment had been of little avail. Staphylococcus pyogenes albus was cultivated from pus, the index for which organism was 1.07 before treatment. The index was raised as the result of treatment to 1.46. Number of injections, 10 ; and opsonic estimations, 9. Duration of treatment 16 weeks. There is still some erythema of the affected parts but there are no more pustules.

C $A$ SE 32.-The patient, a female, aged 25 years, was sent by Dr. Stewart. She had very severe and extensive pustular acne of the face, neck, chest, and back of 15 years' duration. All previous treatment had been ineffectual. Staphylococcus pyogenes albus was isolated from the pus. The staphylococcic opsonic index before treatment, $0 \cdot 77$; highest point reached under treatment, 1.64. Number of staphylococcic injections, 14; and opsonic estimations, 21. Duration of treatment 22 weeks. The chest and back are clear of pustules, but still a few pustules form on the face though in gradually diminishing numbers. It is interesting to note that this patient was treated with a stock vaccine made of various cultures of staphylococci with but little benefit and it was only after she was treated with a vaccine made from a culture of her own particular organism that real improvement began. (Fig. 6.)

CASE 33. - The patient, a male, aged 23 years, was a patient under the care of Dr. Watson of Cottingham. There had been pustular acne of the face and back of seven years' duration, rendering shaving impossible. The staphylococcic index before treatment was 0.88 , rising after injection to maximum of $1 \cdot 6$. Number of injections given, 10 ; and opsonic estimations, 11 . Duration of treatment 13 weeks. The patient is now completely cured. It is interesting to note that the patient had patches of psoriasis on both elbows and knees which were unaffected by the treatment.

CASE 34.- The patient was a male, aged 26 years. An estimation of the staphylococcic opsonic index was taken with others for experimental purposes and was found to be $0 \cdot 73$. At the time it was stated that he was susceptible to staphylococcic infection. Just a month later he presented himself with several large pustules on the face. His staphylococcic opsonic index was then 0.86 . By means of injections the index was raised to $1 \cdot 38$, with rapid disappearance of the pustules and marked improvement in general health. A subsequent slight recurrence promptly yielded to the same treatment.

General remarks on the series of cases. - On the whole we are extremely pleased with the results we have obtained by this mode of treatment. It necessarily entails a very great amount of work and expenditure of time by the bacteriologist but this results in the obtaining of information of the greatest value to the physician or surgeon actually in charge of the patient. We have not used the injections in any haphazard sort of way, but only after careful estimation of the result of each injection at the beginning of the treatment. Later, when we have seen from a study of the opsonic chart how long the result of each injection lasts-what we might term the periodicity or opsonic wave-then the estimation can be made less frequently and the injections continued with certainty.

The amount of benefit derived from the treatment has varied in each case and we do not claim to have cured every patient. It is difficult to generalise in so many distinct and widely differing affections. Broadly speaking, acute case are the more difficult to cure, becanse there may not be time enough to raise the opsonic power to such a degree as to influence the course of the disease ; and at present we do no know much about the proper dosage necessary to do the greatest amount of good without doing evil-i.e., producing a dangerous negative phase. Nor do we profess to be able to cure a case of 15 years chronicity in a like number of weeks.

We think there is a great future for this treatment, if properly applied, for which great honour is due to Sir A. E Wright. Our success, particularly in the two cases of bacillus coli communis infection, supports our opinion that this mode of treatment is capable of great expansion to 
other bacterial diseases and we hope to have an opportunity in the future of reporting further results.

It is obviously impossible to reproduce the charts we have prepared of every case; we have selected what appeared to be the most interesting.

\section{THE DETECTION OF SUGAR IN URINE AND ITS SIGNIFICANCE IN CON- NEXION WITH LIFE ASSURANCE.}

By A. M. KELLAS, PH.D., B.Sc., LECTURER ON CHEMISTRY IN THE MIDDLESEX HOSPITAL MEDICAI SCHOOL;
AND

FRANK J. WETHERED, M.D. LOND., F.R.C.P. LoND., PHYSICLAN TO THE HOSPITAL FOR CONSUMPTION, BROMPTON; AND ASSISTANT PHYSICIAN TO THE MIDDLESEX HOSPITAL.

(From the Laboratories of the Niddlesex Hospital.) (Concluded from p. 106/4)

(2) Creatine $\left(\mathrm{C}_{4} \mathrm{H}_{3} \mathrm{~N}_{3} \mathrm{O}_{2}\right)$ - - A set of experiments were carried out with creatine dissolved in distilled water similar to those with creatinine. Folin ${ }^{1}$ has recently proved that creatine may be present in quantity in normal urine. 0.232 gramme of creatine was dissolved in 20 cubic centimetres of distilled water $=11.6$ milligrammes of creatine per cubic centimetre. This weight was chosen as being equivalent chemically to 10 milligrammes of creatinine per cubic centimetre as used in previous experiments.

\section{TABLE XVI.}

(a) 11.6 milligrammes of creatine per cubic centimetre.

\section{Percentage of} grape sugar.

None present.

$0 \cdot 1$

0.25

0.5

(b) 58 milligrammes of creatine per cubic centimetre $=5$ milligrammes of creatinine per cubic centimetre.

None present. No apparent reaction. The solution remained blue. $0 \cdot 1$ Slowly turned light blue and in two minutes a faint bluish-green precipitate formed, which was distinct in four minutes.

In ten seconds a thick precipitate formed rapidly.

0.5 In two seconds a red precipitate formed rapidly.

(c) 29 milligrammes of creatine per cubic centimetre $=2.5$ milligrammes of creatinine per cubic centimetre.

None present. No apparent reaction. The solution remainer blue. $0 \cdot 1$ A faint opalescence in one and a half minutes, which steadily increased; green turbidity in two minutes. A bright green precipitate on standing.

0.25 In five seconds a yellow precipitate came down, which rapidly turned red.

$0 \cdot 5$ In one and a half seconds a red precipitate formed.

Comparing the above results with those obtained with the corresponding weights of creatinine, as recorded in Tables XIV., XIV. A, and XIV. B, it is readily seen that the inhibiting effect of creatine is much less than is that of creatinine. 2.5 milligrammes of creatinine per cubic centimetre prevent precipitation when 0.1 per cent. of grape sugar is added, whereas the equivalent quantity of creatine -2.9 milligrammes per cubic centimetre-does not do so. The other values correspond. When a precipitate forms with creatine present the time required is usually considerably less than when the corresponding quantity of creatinine is the inhibiting factor.

A few experiments were next carried out to see whether a mixture of creatinine with creatine would behave exactly as one would expect from the results given in Tables XIV. and $\mathrm{XV}$., or whether they would influence each other in any way.

1 Zeitschrift fur Physiologische Chemie, 1904, Band xli., pp. 223-242.
TABLE XVII.

\begin{tabular}{c|c}
$\begin{array}{c}\text { Percentage of } \\
\text { sugar. }\end{array}$ & $\begin{array}{c}\text { Aqufous solution containing } 5 \text { milligrammes of } \\
\text { creatinine and 5.8 milligrammes of creatine per } \\
\text { cubic centimetre. Jesult of boiling with an } \\
\text { equal volume of Fehling's solution. }\end{array}$ \\
\hline 0.25 & $\begin{array}{c}\text { Turned light blue and then green and in five } \\
\text { minutes a faint green precipitate came down. } \\
0.5\end{array}$ \\
In 30 seconds a green precipitate separated, \\
which changed to yellow.
\end{tabular}

TABLE XVII. A.

\begin{tabular}{c|c}
$\begin{array}{c}\text { Percentage of } \\
\text { sugar. }\end{array}$ & $\begin{array}{c}\text { Aqueous solution containing } 2.5 \text { milligrammes of } \\
\text { creatinine and } 2.9 \text { milligrammes of creatine per } \\
\text { cubic centimetre. Result of boiling with an } \\
\text { equal volume of Fehling's solution. }\end{array}$ \\
\hline 0.1 & $\begin{array}{c}\text { No precipitate in four hours. } \\
0.25\end{array}$ \\
$\begin{array}{c}\text { In } 30 \text { seconds a green precipitate began to come } \\
\text { down, which gradually changed to yellow. }\end{array}$
\end{tabular}

The above results indicate, as was to be expected from the preceding experiments as recorded in Tables XIV. and XV., that creatinine is the more important retarding factor of the two; in fact, the results are very similar to those of Tables XIV. A. and XIV.B.

(3) Uric acid $\left(\mathrm{O}_{5} \mathrm{H}_{4} \mathrm{~N}_{4} \mathrm{O}_{3}\right)$ and urates.-Since, according to the late Sir W. Roberts, ${ }^{2}$ the urates present in normal urine consist entirely of quadriurates of sodium, potassium, and ammonium, experiments were chiefly carried out with ammonium quadriurate and sodium urate, but a few comparison experiments were a'so made with uric acid.

Prelimincury experiments.-1. (a) Water was saturated with ammonium quadriurate: (1) at $15^{\circ}$, (2) at $40^{\circ}$, and (3) at $60^{\circ} \mathrm{C}$., by digesting for over four hours at the temperatures named. In each case on boiling two cubic centimetres with two cubic centimetres of Fehling's solution a slight red precipitate formed in a few minutes. (b) Urine (specific gravity 1014) was saturated with ammonium quadriurate by digesting for four hours: (1) at $40^{\circ}$ and (2) at $60^{\circ} \mathrm{C}$. On boiling two cubic centimetres with two cubic centimetres of Fehling's solution no red precipitate formed, but after standing for some time a white precipitate, which might have been cuprous urate or phosphates, settled. 2 An analogous series of experiments carried out with sodium urate solution and with urine saturated with sodium urate at $15^{\circ}, 40^{\circ}$. and $60^{\circ} \mathrm{C}$. gave similar results, a red precipitate forming in less than three minutes with the aqueous solution, and no precipitate forming with the urine. The precipitates from the aqueous solution in this case formed more readily than in the case of the similar solutions containing ammonium quadriurate.

The above results, which agree with those of MacLean, ${ }^{3}$ might be due either to the quantity of urate in aqueous solution being much greater than that present in urine (Roberts emphasises the comparative insolubility of urates, when sodium salts like the chloride are present) or to the creatinine, \&c., exerting an inhibiting influence, or to both these factors.

In order to determine whether the quantity in aqueous solution was much greater than that present in urine, a few quantitative determinations of uric acid in moderately con. centrated samples of urine (specific gravity 1025) were carritd out by the Fokker-Salkowski process as modified by Hopkins with the following results :-

TABLE XVIII.

\begin{tabular}{|c|c|c|}
\hline $\begin{array}{c}\text { Temperature } \\
\text { of satura- } \\
\text { tion } \\
\text { (Centigrade). }\end{array}$ & Nature of solution. & $\begin{array}{l}\text { Weight per } 1000 \\
\text { cubic centimetres } \\
\text { calculated as } \\
\text { uric acid. }\end{array}$ \\
\hline $14^{\circ}$ & Sodium urate in distilled water. & 0.9 gramme. \\
\hline $40^{\circ}$ & Ditto. & 1.6 grammes. \\
\hline $14^{\circ}$ & Sodium urate in urine. & 0.9 gramme. \\
\hline $40^{\circ}$ & Ditto. & 1.05 grammes. \\
\hline $14^{\circ}$ & $\begin{array}{l}\text { Ammonium quadriurate in distilled } \\
\text { water. }\end{array}$ & 0.49 gramme.* \\
\hline $40^{\circ}$ & Ditto. & $" \quad *$ \\
\hline $14^{\circ}$ & Ammonium quadriurate in urine. & $0.85 \quad$, \\
\hline $40^{\circ}$ & Ditto. & $1.0 \quad$, \\
\hline
\end{tabular}

The above values show that the quantities present should,

\footnotetext{
2 Allbutt's System of Medicine, vol. iti.
}

9 Biochemical Journal, 1906, p. 3. 